\title{
Oxidation of metallic glass thin films: a combined EPMA and XPS investigation into the composition and thickness of oxidized surfaces
}

William Nachlas ${ }^{1}$, Sachin Muley ${ }^{2}$, Aurelien Moy ${ }^{2}$, John Sunderland ${ }^{2}$, John Fournelle ${ }^{1}$ and Paul Voyles ${ }^{3}$

${ }^{1}$ Department of Geoscience, University of Wisconsin-Madison, United States, ${ }^{2}$ University of WisconsinMadison, United States, ${ }^{3}$ University of Wisconsin Madison, United States

Metallic glass thin films (MGTFs) are a recently developed alternative to conventional alloy thin films that exhibit several unique material properties beneficial in applications from biomedical devices to electrical components [1,2]. The surface of MGTFs is characterized by ultra low coefficient of friction, and combined with Zr-based MGTFs' biocompatibility, makes them an advantageous coating material for minimally-invasive surgical devices and syringes [3]. Minimizing surface oxidation is critical to longterm utility of Zr-based MGTFs in biomedical applications and needs to be well understood for design considerations. We combined thin film analysis by electron probe microanalysis (EPMA) with X-ray photoelectron spectroscopy (XPS) to quantify the composition and thickness of surface oxidation layers of Zr-based MGTFs.

Thin films were deposited by employing an in-house built high vacuum direct current magnetron sputtering tool. An arc-melted alloy target with nominal compositions of $\mathrm{Zr}_{55} \mathrm{Cu}_{30} \mathrm{Al}_{10} \mathrm{Ni}_{5}$ (at. \%) was commercially acquired. The base pressure of the vacuum vessel was better than $1 \times 10^{-7}$ Torr. The operating pressure of process gas (Ar) was 4.3 mTorr during deposition as measured by a 275i Pirani-style pressure gauge made by Kurt J. Lesker Company.

Sputter deposited samples investigated in this study are comprised of three layers: (1) a substrate of $\mathrm{Si}<$ 001 > wafer, (2) two types of MGTF of base composition $\mathrm{ZrCuAlNi}$ with thicknesses ranging from 15$1500 \mathrm{~nm}$, and (3) surface oxidation layer of composition $\mathrm{ZrO}_{2}$ and unknown thickness. Three MGTF samples with nominal composition $\mathrm{Zr}_{55} \mathrm{Cu}_{30} \mathrm{Al}_{10} \mathrm{Ni}_{5}$ were fabricated for this study (nominally 50, 500, $1500 \mathrm{~nm}$ thickness), and two samples with the same nominal composition were used from a previous study (nominally $15 \mathrm{~nm}$ thickness). FE-SEM was used to measure cross sectional thickness of the MGTF from cleaved samples. XRD was used to confirm amorphous structure of MGTF samples used for this analysis. XPS analysis reveals high energy shifts in $\mathrm{Zr} 3 \mathrm{~d}$ orbitals indicating that surface oxidation layers are dominantly $\mathrm{ZrO}_{2}$. XPS data acquired in depth profiling mode are used as an independent constraint on layer thickness.

Analysis of characteristic X-ray emission from MGTF samples was performed using EPMA [4]. X-ray intensities for O-K $\alpha$ (LPC0), Al-K $\alpha$ (LTAP), Si-K $\alpha$ (LTAP), Ni-K $\alpha$ (LLIF), Cu-K $\alpha$ (LLIF), and Zr-L $\alpha$ (LPET) were acquired using a Cameca SX-Five Field Emission EPMA instrument equipped with Schottky Field Emission source and five wavelength-dispersive spectrometers (WDS). Experimental X-ray intensities were acquired from five unknown MGTF samples and a suite of standard materials (pure metals for $\mathrm{Al}, \mathrm{Si}, \mathrm{Ni}, \mathrm{Cu}, \mathrm{Zr}$, and synthetic $\mathrm{Fe}_{3} \mathrm{O}_{4}$ for $\mathrm{O}$ ). Measurements were acquired at 10, 12, 15, 20, 25, and $30 \mathrm{kV}$ accelerating voltage.

X-ray intensities of all elements decrease with increasing accelerating voltage except for $\mathrm{Si}$, which increases with voltage. This can be seen clearly upon inspection of data from the nominally 50, 500, and $1500 \mathrm{~nm}$ MGTF samples (Fig. 1). The increased activation volume at higher $\mathrm{kV}$ generates a larger proportion of X-rays from the substrate relative to the thin films. At low $\mathrm{kV}, \mathrm{Si}$ k-ratios close to zero 
indicate minimal interaction with the substrate for nominally 500 and $1500 \mathrm{~nm}$ samples. Trends in $\mathrm{O} \mathrm{k}-$ ratios are independent of sample thickness and show no significant variation between samples.

Elemental composition and thickness of multi-layered samples was calculated using the BadgerFilm thin film analysis program [5,6]. BadgerFilm calculates theoretical k-ratios with the PAP phi-rho-z algorithm [7] and modified phi-rho-z matrix correction to calculate characteristic and Bremsstrahlung fluorescence effects. The program uses a non-linear fitting algorithm to match calculated k-ratios to experimental kratios acquired from a range of accelerating voltages to determine composition and thickness of stratified samples (Fig. 2). Input parameters include experimental k-ratios from multiple $\mathrm{kV}$ conditions and initial guesses for material composition/density and layer thickness. The program converges on a solution for the composition and thickness of both the MGTF and surface oxidation layer. The thickness of surface oxidation layers was found to range from 8-110 ̊ and correspond with time since sputter deposition.
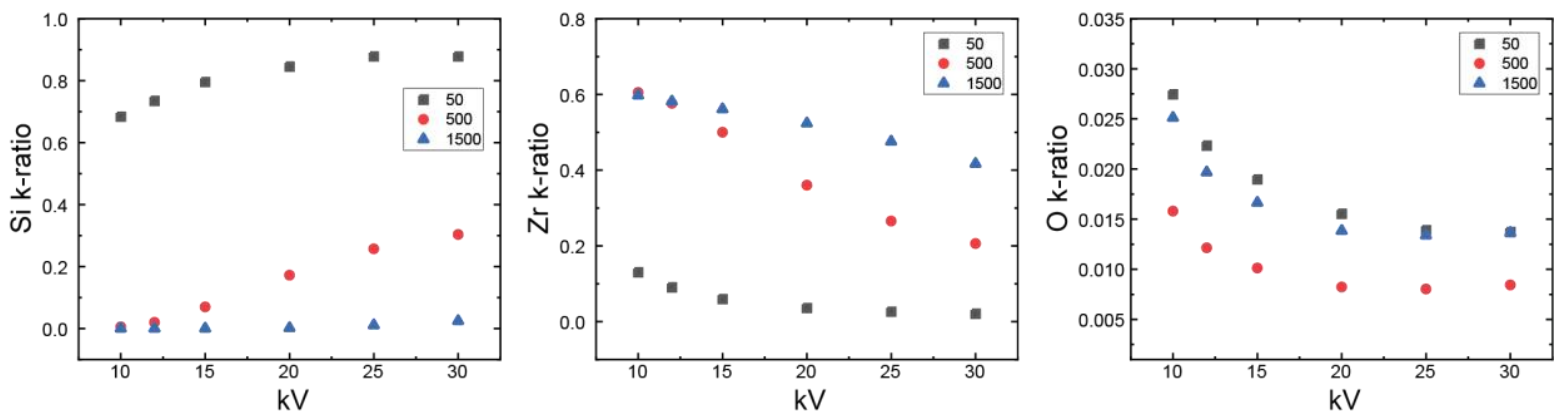

Figure 1. Experimental k-ratios for $\mathrm{Si}, \mathrm{Zr}$, and $\mathrm{O}$ from nominally 50, 500, and $1500 \mathrm{~nm}$ metallic glass thin films.
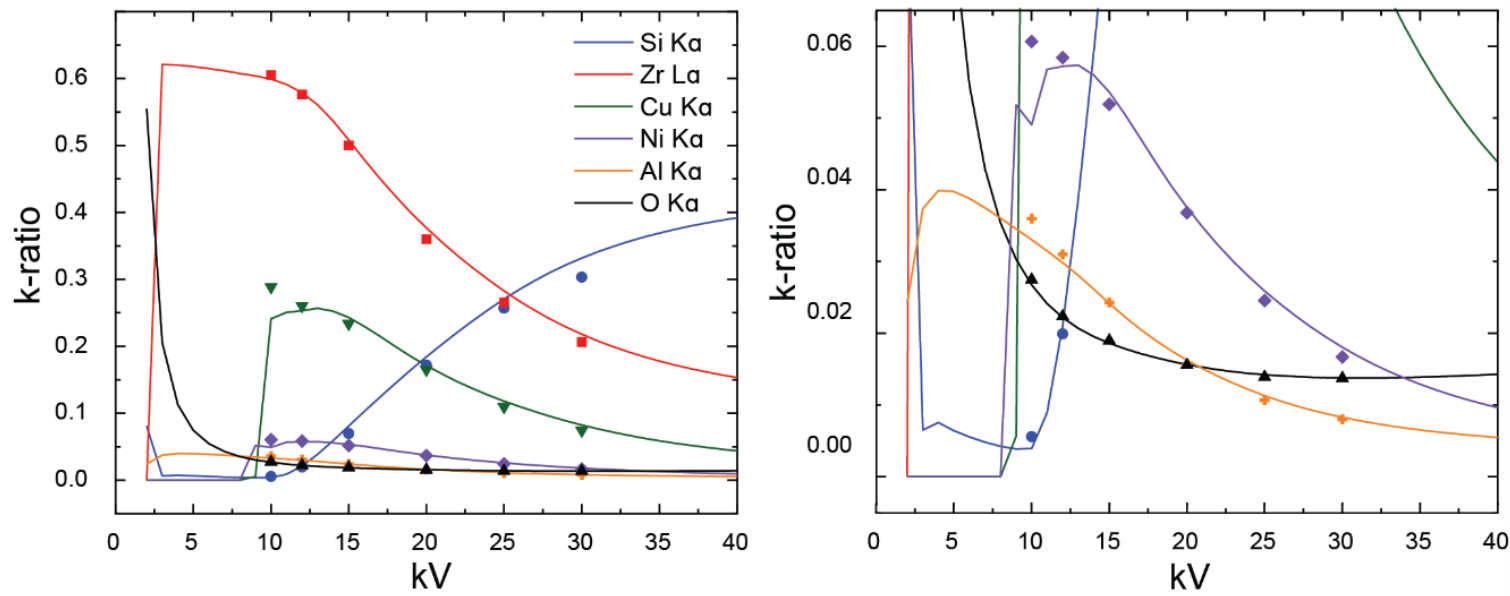

Figure 2. The BadgerFilm program uses a non-linear fitting algorithm to match calculated k-ratios to experimental k-ratios acquired from a range of accelerating voltages, enabling quantitative determination of composition and thickness of stratified samples. This plot shows results from a $470 \mathrm{~nm}$ MGTF of composition $\mathrm{Zr}_{53} \mathrm{Cu}_{30} \mathrm{Al}_{10} \mathrm{Ni}_{7}$ with $71 \AA \mathrm{ZrO}_{2}$ surface layer.

References

[1] Diyatmika, Wahyu, et al. (2015) Thin film metallic glasses in optoelectronic, magnetic, and electronic applications: a recent update. Current Opinion in Solid State and Materials Science 19.2: 95-106. 
[2] Kuo, Pei-Hung, Lee, Joseph, and Duh, Jenq-Gong (2018) Ultra-thin metallic glass film of $\mathrm{Zr}-\mathrm{Cu}-\mathrm{Ni}-$ $\mathrm{Al}-\mathrm{N}$ as diffusion barrier for $\mathrm{Cu}-\mathrm{Si}$ interconnects under fully recrystallized temperature. Journal of Materials Science: Materials in Electronics 29.22: 19554-19557.

[3] Chu, Jinn P., et al. (2016) Non-stick syringe needles: Beneficial effects of thin film metallic glass coating. Scientific reports $6.1: 1-7$.

[4] Llovet, Xavier, et al. (2021) Electron probe microanalysis: a review of recent developments and applications in materials science and engineering. Progress in Materials Science 116: 100673.

[5] Moy, Aurélien, and Fournelle, John (2021a) $\phi(\rho z)$ Distributions in Bulk and Thin Film Samples for EPMA. Part 1: A Modified $\phi(\rho z)$ Distribution for Bulk Materials, Including Characteristic and Bremsstrahlung Fluorescence. Microscopy and Microanalysis, 1-18.

[6] Moy, Aurélien, and Fournelle, John (2021b) $\phi(\rho z)$ Distributions in Bulk and Thin-Film Samples for EPMA. Part 2: BadgerFilm: A New Thin-Film Analysis Program. Microscopy and Microanalysis, 1-13. [7] Pouchou, Jean-Louis, and Pichoir, Françoise (1991) Quantitative analysis of homogeneous or stratified microvolumes applying the model PAP, in Electron Probe Quantitation. Plenum Press, 31-75. 